Diskussionspapiere des

Europäischen Instituts für Sozioökonomie e. V.

Working Papers of the

European Institute for Socioeconomics

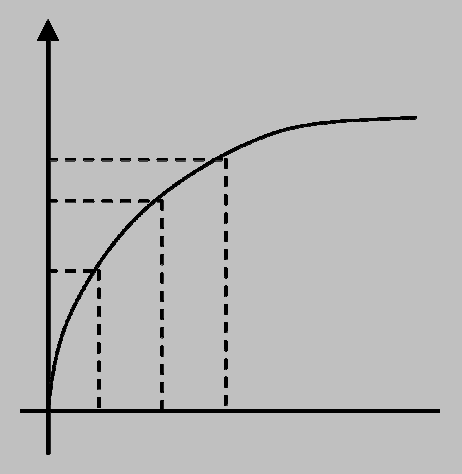

\title{
Match Quality, Crowding Out, and Crowding In: Empirical Evidence for German Sports Clubs
}

Christoph Behrens, Eike Emrich, Martin Hämmerle \& Christian Pierdzioch

Nr. 21 


\section{Christoph Behrens,}

Department of Economics, Helmut Schmidt University, Holstenhofweg 85,

P.O.B. 700822,

22008 Hamburg, Germany.

Tel. +49 4065413859 ,

E-mail: christoph.behrens@hsuhh.de

Eike Emrich,

Department of Sports Science, Saarland University, Campus Buildung B8.2

66123 Saarbrücken, Germany.

Tel. +49681302 4170,

E-mail: e.emrich@mx.uni-saarland.de

\section{Martin Hämmerle,}

Department of Sports Science, Saarland University, Campus Buildung B8.2

66123 Saarbrücken, Germany.

Tel. +4963134112 54,

E-mail: martin.haemmerle@sportbundpfalz.de

\section{Christian Pierdzioch,}

Department of Economics, Helmut Schmidt University, Holstenhofweg 85,

P.O.B. 700822,

22008 Hamburg,

Germany. Tel. +49 4065413007 ,

E-mail: c.pierdzioch@hsuhh.de

\section{(C) 2017}

Europäisches Institut für Sozioökonomie e. V. / European Institute for Socioeconomics

c/o Universität des Saarlandes

Sportwissenschaftliches Institut

Arbeitsbereich Sportökonomie und Sportsoziologie

Campus, Gebäude 8.1

66123 Saarbrücken

http://www.soziooekonomie.org 


\title{
Match Quality, Crowding Out, and Crowding In: Empirical Evidence for German Sports Clubs
}

May 2017

\begin{abstract}
Volunteering can be interpreted as a process of search that matches volunteer labor supply with demand for volunteer work by voluntary organizations like sports clubs. Using novel data from an online questionnaire study of German sports club members, we constructed a match quality index (MQI) that measures the outcome of this search process: the congruence of motives for doing volunteer work and the utility experiences derived from volunteer work. The MQI is higher on average for volunteers who would increase their work effort if their sports club received additional public subsidies or other volunteers would increase their work (crowding-in effect). The MQI is also higher on average for volunteers who would increase their work effort if other volunteers would decrease their work (crowding-out effect). Furthermore, match quality exhibits a positive correlation with important outcomes of volunteering like volunteer satisfaction, labor supply, and volunteers' confidence that they meet the requirements of their volunteer positions. The MQI is positively correlated with a bridging, but also with a bonding element of social capital.
\end{abstract}

Keywords: Match quality; Crowding out; Economics of Volunteering; Sports clubs

\section{Authors:}

Christoph Behrens, Department of Economics, Helmut Schmidt University, Holstenhofweg 85, P.O.B. 700822, 22008 Hamburg, Germany. Tel. +49 406541 3859, E-mail: christoph.behrens@hsuhh.de.

Eike Emrich, Department of Sports Science, Saarland University, Campus Buildung B8.2 66123 Saarbrücken, Germany. Tel. +49 681302 4170, E-mail: e.emrich@mx.uni-saarland.de.

Martin Hämmerle, Department of Sports Science, Saarland University, Campus Buildung B8.2 | 66123 Saarbrücken, Germany. Tel. +49 63134112 54, E-mail: martin.haemmerle@sportbundpfalz.de.

Christian Pierdzioch*, Department of Economics, Helmut Schmidt University, Holstenhofweg 85, P.O.B. 700822, 22008 Hamburg, Germany. Tel. +49 406541 3007, E-mail: c.pierdzioch@hsuhh.de.

* Corresponding author. 


\section{Introduction}

In a world of imperfect information volunteering can be viewed as a process of search (Schiff, 1980). This process has at least two aspects (Emrich \& Pierdzioch, 2016). First, an individual who plans to become a volunteer needs to gather information about whether a nonprofit organization is a good match for his or her humanitarian or ideological values. A volunteer may also collect information on the quality of the output of a nonprofit organization and the efficiency with which it transforms volunteer inputs into output. Second, once a volunteer has decided to work for a specific nonprofit organization a key issue is to gather information about the work atmosphere between the paid staff and other volunteers. Importantly, a volunteer needs to find out whether his or her volunteer work allows motives and environmental affordance (Stukas, Worth, Clary, \& Snyder, 2009) or motives and utility experiences (Emrich \& Pierdzioch, 2016) to be matched. Match quality, interpreted as the extent to which a volunteer's motives are fulfilled, is likely to influence various outcomes of volunteering like satisfaction, involvement, and the willingness to continue volunteering (e.g., Tschirhart, Mesch, Perry, Miller, \& Lee, 2001). Researchers have, therefore, studied how match quality can be measured, how it affects outcomes, and how it is linked to organizational structure and socioeconomic variables (Davis, Hall, \& Meyer, 2005; Stukas et al., 2009; Emrich \& Pierdzioch, 2016).

For the management of a nonprofit organization, not only satisfaction, involvement, and the willingness to continue volunteering is an important outcome of volunteering. Rather, it is also crucial to understand whether and, if so, how volunteers would change their labor supply when other volunteers would adjust their work effort or a nonprofit organization would receive additional public subsidies. If volunteer labor supply would decrease (increase) in such a case then the labor supply of volunteers, and volunteer labor supply and public funding, would be substitutes (complements). At an operative level, managing a nonprofit organization would be complicated if the labor supply of volunteers would move in tandem (complementarity) rather than in opposite directions (substitutability). Studying the substitutability or complementarity of volunteer labor supply is also important from the perspective of economic theory. Economic theories of volunteer labor supply can be broadly categorized into publicgoods theories, private-consumption theories, and human-capital theories (see, e.g., Ziemek, 2006; Emrich \& Pierdzioch, 2015).

Public-goods theories (Roberts, 1984; Bergstrom, Blume, \& Varian, 1986; among others) predict that a volunteer is only interested in the aggregate supply of a public good. Such theories predict that, when other volunteers increase their labor supply or the state subsidizes 
a nonprofit organization, a volunteer decreases his or her labor supply to make sure that the aggregate supply of the public good is unchanged (crowding-out effect). In contrast, private-consumption theories (see, for example, Andreoni, 1989; Harbough, 1998) predict that a volunteer derives in-process benefits from doing volunteer work (e.g., a 'warm-glow' feeling), implying that state subsidies or changes in the labor supply of other volunteers do not affect his or her labor-supply decision. Finally, human capital theories (e.g., Menchik \& Weisbrod, 1987) predict that volunteers mainly aim at accumulating job-market skills and job-relevant contacts. Because meeting other volunteers is easier in nonprofit organizations that employ many volunteers, or simply because of signaling considerations, a volunteer should increase his or her labor supply when other volunteers increase their work effort. Similarly, state subsidies may increase the return on the volunteers' time investment, resulting in a crowding-in effect (for further discussion, see Ziemek, 2006).

Given their importance for discriminating between economic theories of volunteering, much significant empirical work has been done to shed light on potential crowding-out and crowdingin effects (for earlier studies, see Abrams \& Schitz, 1978; Kingma, 1989; Steinberg, 1991; Payne, 1998). In this strand of research, most researchers have studied the effect of government subsidies on private donations of money to charitable and nonprofit organizations. Results of this research are mixed with some researchers reporting results consistent with a crowding-out effect and other researchers documenting evidence of a crowding-in effect (for a meta-analysis, see De Wit \& Bekkers, 2016). Evidence of a crowding-out effect has been reported by, for example, Ribar and Wilhelm (2002), Simmons and Emanuele (2002), Ferris and West (2003), Kim and Van Ryzin (2013), where the magnitude of the reported effect varies across studies. Evidence of a crowding-in effect has been documented by Khanna and Sandler (2000), Smith (2007), Heutel (2012), and Sokolowski (2013), among others. Crowding-in effects have also been observed for sport clubs. Wicker, Breuer, and Hennings (2012) find that in German sport clubs government subsidies crowd-in private subsidies. Still other researchers have emphasized the possibility that the link between public subsidied and private donations is nonlinear, with low (high) levels of public subsidies crowding in (out) private donations (Borgonovi, 2006; Nikolova, 2015). Yet other researchers have emphasized that the sign of the effect of public subsidies on private donations may differ across sectors (Brooks, 2000; De Wit, Bekkers, \& Groenou, 2016; Sokolowski, 2013) and across levels of government (that is, central government versus multiple levels of government, see De Wit \& Bekkers, 2016). Researchers also have emphasized that donors are imperfectly informed about public subsidies (Horne, Johnson, \& Van Slyke, 2005) and that charitable organizations may offset public subsidies by reducing fundraising efforts (Andreoni \& Payne, 2003, 2011). 
Using novel data from an online questionnaire study of volunteers of German sports clubs, we contribute to the debate on the crowding-out/crowding-in effect by studying the willingness of volunteers to decrease or increase their labor supply when other volunteers would change their work effort or the sports clubs would receive additional subsidies from the state. Studying nonprofit sports clubs is interesting for several reasons. Nonprofit sports clubs are a quantitatively important subgroup of nonprofit organizations, they are the main suppliers of sports for broad groups of the population, and their grassroots work is indispensable for sighting athletes for professional sport. Nonprofit sports clubs may create positive external effects that contribute to the overall welfare of society, and they are a foundation of civil society not at least because they heavily rely on the contributions of volunteers. Because volunteerism is of key importance for nonprofit sports clubs it is of key interest to study whether volunteers of nonprofit sports clubs view their contributions of time as substitutes or complements and whether and, if so, how the substitutability or complementarity of volunteers' labor supply changes with variations in match quality.

Using volunteers' answers to our questions concerning their utility experiences from volunteering and motives for doing volunteer work, we constructed a Match Quality Index (MQI) as in Stukas et al. (2009) and Emrich and Pierdzioch (2016). We found that the MQI is higher on average for volunteers who would increase their work effort if other volunteers would increase their work effort or if their sports club would receive additional public subsidies. Further, we found that the MQI is higher on average for volunteers who would increase their work effort if other volunteers would decrease their work. These findings contribute in four important ways to the relatively recent literature on volunteerism and match quality, on the one hand, and the extensive literature on the crowding-out/crowding-in hypothesis, on the other hand. First, our results shed light on how the work effort of other volunteers affects volunteers' willingness to expand or contract their own labor supply. Hence, we focus on volunteers' donations of time rather than donations of money, which have been the subject of much earlier research. Second, we not only present results for public subsidies but also asked how volunteers would change their labor supply if other volunteers who volunteer in the same sports club would change their work effort. Third, our findings establish that match quality is systematically linked to an important outcome of volunteering, namely the willingness of volunteers to change their labor supply when others also do so. Fourth, our findings reveal an interesting asymmetry. Our findings suggest that match quality reinforces a complementarity of volunteer labor supply and, thus, a crowding-in effect is at work when others (including the state) would increase their contributions. In contrast, match quality reinforces a substitutability of volunteer labor supply consistent with a crowding-out effect in a scenario in which others would reduce their 
work effort.

Our findings also show that the MQI is correlated with several other important outcomes of volunteering. In line with recent research on match quality, we found that volunteer satisfaction and hours volunteered per week increase in match quality. Furthermore, the MQI is positively correlated with volunteers confidence that they meet the requirements of a volunteer position. Consistent with findings reported by Stukas, Daly, and Cowling (2005), we found that the MQI is positively correlated with social capital as measured in terms of generalized trust in others. At the same time, however, we found that the MQI is on average higher for those volunteers who articulated that other members of their sports club are more trustworthy than other members of society. Consistent with results reported by Behrens, Emrich, Meyer, and Pierdzioch (2016), match quality thus seems to strengthen a bridging, but also a bonding element of social capital.

We proceed as follows. In Section 2, we describe the instrument and data, In Section 3, we summarize our empirical findings. In Section 4, we conclude.

\section{The Instrument and the Data}

\section{$2.1 \quad$ Instrument}

We collected the data used in this research by means of an online questionnaire study that we conducted from May 29th to June 30th 2016. The link to the online questionnaire was sent to registered volunteers in the database of Sportbund Pfalz e.V. (regional sports association in Rhineland-Palatine, Germany). We asked volunteers several questions concerning their volunteer work, their motives for doing volunteer work, their utility experiences, and their sociodemographic status. Filling in the questionnaire consumed approximately 20-30 minutes of time. In total, $N=3,067$ volunteers participated in the survey (but not all volunteers answered all questions).

\subsection{Match Quality Index}

Table 1 summarizes the ten dimensions of volunteers' motives and utility experiences that we used to compute a match-quality index (MQI), where we had available data for $N=2,307$ volunteers. The ten dimensions cover altruistic motives and utility experiences correlated 
Table 1: Motive and Utility Dimensions Used to Construct the MQI

\begin{tabular}{lrr}
\hline \hline Dimension & $\begin{array}{r}\text { Motive } \\
\text { (mean) }\end{array}$ & $\begin{array}{r}\text { Utility experience } \\
\text { (mean) }\end{array}$ \\
\hline to gain attention within the club & 1.78 & 3.65 \\
to gain reputation and influence within the club & 1.90 & 3.18 \\
to defend one's interests & 2.63 & 3.01 \\
to help others & 4.19 & 4.04 \\
to have fun & 4.19 & 4.22 \\
to spend leisure time in a worthwhile manner & 3.55 & 3.76 \\
to work together with other individuals & 4.03 & 4.03 \\
to improve job-market prospects & 1.57 & 1.72 \\
to bring about changes in politics & 1.82 & 1.55 \\
to contribute to small-scale developments in society & 3.85 & 3.18 \\
\hline \hline
\end{tabular}

with the public-goods model, egoistic and consumption-oriented motives and utility experiences that correspond to the private-consumption model, and job-market oriented motives and utility experiences that represent the human-capital model.

We asked volunteers to rank separately every motive and every utility experience on a 5-point scale from 'do not agree' to 'totally agree'. Like Stukas et al. (2009) and Emrich and Pierdzioch (2016), we then aggregated the information on the ten motives and utility experiences to a total match-quality index (MQI) as follows:

$$
\mathrm{MQI}_{i}=\sum_{j=1}^{10} \text { motive }_{i, j} \times \text { utility }_{i, j},
$$

where the index $i$ represents a volunteer, and the index $j$ represents a motive/utility dimension. Hence, for each volunteer a motive dimension and the corresponding utility dimension were combined as multiplicative factors. We then summed up over all ten motive-utility dimensions for which we had collected data to form a volunteer-specific MQI.

Match quality along a certain motive/utility dimension is high if both the motive and the utility receive a high rank. Moreover, if both the motive and the utility receive a high rank than this specific dimension is important for a volunteer, and so this dimension receives a high weight in the construction of the MQI. The opposite is true for the case in which a motive dimension and the corresponding utility dimension receive a low rank. In this case, even though match quality is also high, a motive/utility dimension receives a small weight in the construction of the MQI because it is unimportant for a volunteer. Finally, if there is a mismatch along a certain dimension (e.g., a motive dimension receives a low rank whereas the corresponding 
Figure 1: Match-Quality Index (MQI)

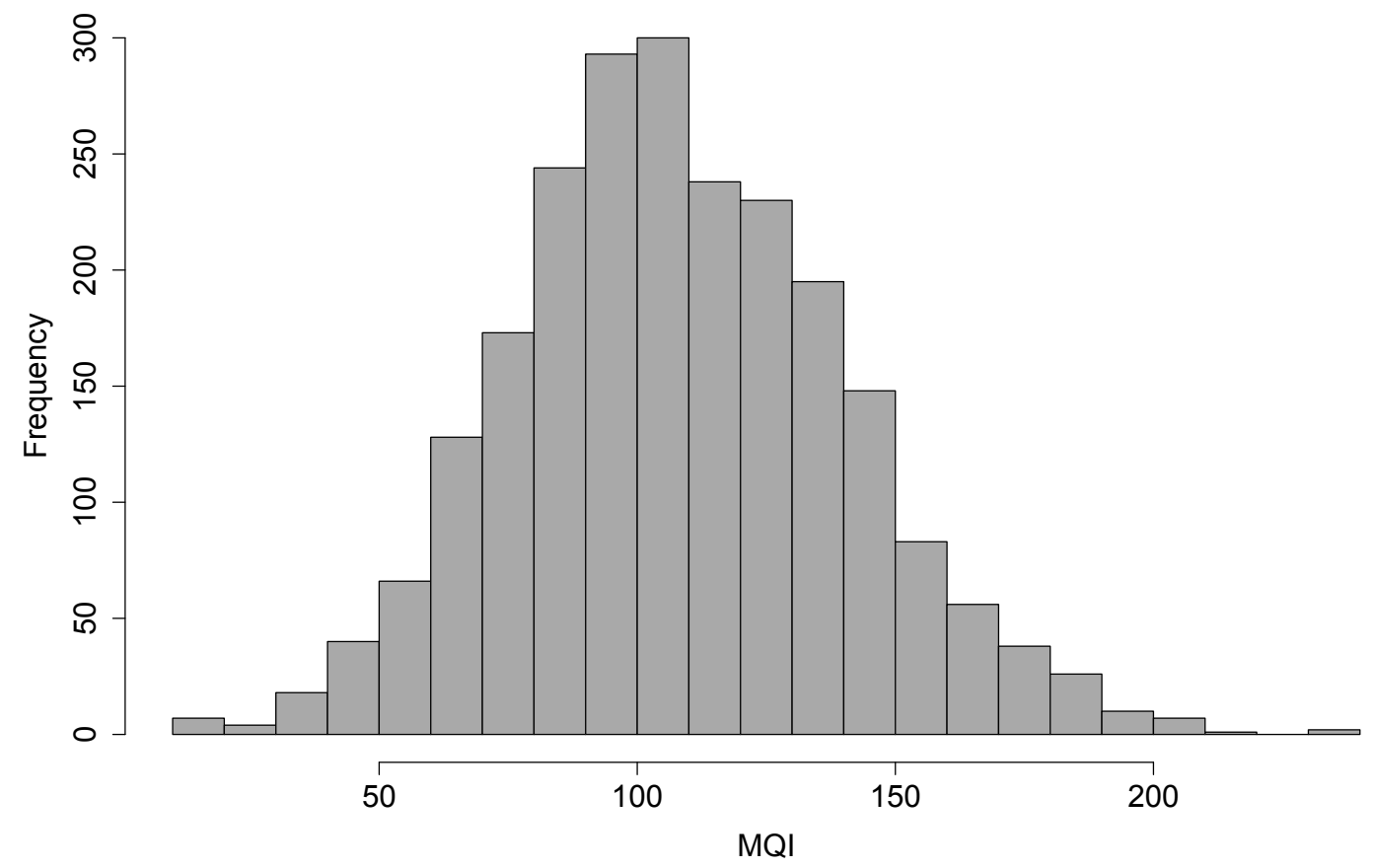

utility dimension receives a high rank), this dimension also receives a comparatively small weight in the computation of the MQI.

Figure 1 plots the MQI. The MQI has a bell-shaped frequency distribution with a mean of 108.5 index points, a median of 106 index points, a standard deviation of 32.37 index points, and $\min (\max )$ of $10(240)$ index points.

\subsection{Outcomes of Volunteering and Social Capital}

On average, a volunteer in our sample volunteers about seven hours per week (median $=5$ hours per week, standard deviation approximately 6 hours per week, volunteers who answered that they would work more than 40 hours per week were deleted from the sample). We asked volunteers about the experiences they gained while volunteering in their sports club, and we asked social-capital questions. Volunteers could answer on a 5-point scale (results are for those volunteers for which we have data on the MQI).

Table 2 summarizes descriptive statistics of personal experiences of an individual's voluntary work. For more than $77 \%$ of the participants the volunteer work in their sports club is an 
Table 2: Outcomes of Volunteering

\begin{tabular}{llr}
\hline \hline Questions/Statements & Answers & Percentages \\
\hline How important is your volunteer work to you? & Very important & 23.42 \\
& Important & 53.77 \\
& So, so & 19.08 \\
& Less important & 3.29 \\
& Unimportant & 0.44 \\
\hline Are you up to the challenges of your voluntary work? & Always & 28.24 \\
& Most of the time & 70.16 \\
& Sometimes & 1.26 \\
& Seldom & 0.26 \\
& Never & 0.09 \\
\hline How content are you with your volunteer work? & Very content & 20.85 \\
& Content & 57.43 \\
& So, so & 19.26 \\
& Discontent & 1.86 \\
How content are you with your club's support? & Very Discontent & 0.59 \\
\hline \hline
\end{tabular}

important or very important part of live. Only less than $4 \%$ answered that volunteering is less important or unimportant to them. Regarding the tasks and challenges of their volunteer work, most participants are quite confident. Only $1.61 \%$ of the volunteers said they were sometimes, seldom, or never up to the challenges of their volunteer work, whereas $70.16 \%$ are most of the time and $28.24 \%$ are always up to the task. When asked about the satisfaction with their volunteer work most volunteers claim to be content $(57.43 \%)$ or very content $(20.85 \%)$ and only $2.45 \%$ are either discontent or very discontent.

When asked about the satisfaction with their club's support, almost $9 \%$ of volunteers answered that they were at least discontent, while $51.53 \%$ answered that they were content with their club's support and $18.01 \%$ are very content. The interpretation of these descriptive statistics, however, should not be stretched too far as they most likely reflect at least to some extent a selection bias because volunteers who are very discontent with their voluntary work or the situation in their sports club presumably terminated volunteering for that sports club and, thus, do not show up in our sample. 
Table 3: Social Capital

\begin{tabular}{llr}
\hline \hline Questions/Statements & Answers & Percentages \\
\hline The sense of community in our club is declining. & Fully disagree & 14.01 \\
& Mostly disagree & 16.36 \\
& So, so & 38.83 \\
& Mostly agree & 19.23 \\
& Fully agree & 11.57 \\
\hline I generally trust others. & Fully disagree & 1.08 \\
& Mostly disagree & 5.59 \\
& So, so & 32.88 \\
& Mostly agree & 42.41 \\
& Fully agree & 18.04 \\
\hline I generally trust members of my club more than others. & Fully disagree & 30.57 \\
& Mostly disagree & 13.66 \\
& So, so & 32.74 \\
& Mostly agree & 17.66 \\
& Fully agree & 5.37 \\
\hline \hline
\end{tabular}

Table 3 summarizes results for social capital. Regarding the sense of community in a volunteer's sports club the answers are quite evenly distributed. Most participants neither agree (nor disagree) that the sense of community in their sports club is declining (38.83\%). $30.37 \%$ mostly or fully disagree with that statement, whereas $30.8 \%$ mostly or fully agree with it. Concerning general trust in others, $42.41 \%$ of the volunteers mostly agree and $18.04 \%$ fully agree with the statement 'I generally trust others'. Only $6.67 \%$ disagree at least partly and $32.88 \%$ neither agree nor disagree. When asked in how far they agree with the statement 'I generally trust members of my club more than others', $44.23 \%$ of volunteers mostly or fully disagree, $32.74 \%$ neither agree nor disagree, and $23.03 \%$ at least partly agree.

\subsection{Crowding Out and Crowding In}

In order to study the crowding-out/crowding-in hypothesis, we asked volunteers what they would do if other volunteers of their sports club would expand labor supply by one hour per week. Volunteers could answer on a 7-point scale from 'I would decrease my labor supply by more than one hour' to 'I would increase my labor supply by more than one hour'. We asked whether they would expand labor supply by more or less than one hour because the strength of a crowding-out/crowding-in effect has been studied in earlier research. 
Table 4: Crowding-Out/Crowding-In Questions

\begin{tabular}{|c|c|}
\hline Answers & Percentages \\
\hline \multicolumn{2}{|l|}{ Panel A } \\
\hline \multicolumn{2}{|c|}{$\begin{array}{c}\text { Other volunteers increase their labor supply by one hour per week. } \\
\text { How would you adapt your labor supply? }\end{array}$} \\
\hline 1 No - Reduction by more than one hour & 2.40 \\
\hline 2 No - Reduction by one hour & 1.75 \\
\hline 3 No - Reduction by less than one hour & 0.92 \\
\hline 4 No - Unchanged & 62.08 \\
\hline 5 Yes - Increase by less than one hour & 3.51 \\
\hline 6 Yes - Increase by one hour & 16.19 \\
\hline 7 Yes - Increase by more than one hour & 13.15 \\
\hline \multicolumn{2}{|l|}{ Panel B } \\
\hline \multicolumn{2}{|c|}{$\begin{array}{l}\text { Other volunteers reduce their labor supply. } \\
\text { How would you adapt your labor supply? }\end{array}$} \\
\hline 1 I compensate the reduction by working more & 47.16 \\
\hline 2 I do not care & 49.27 \\
\hline 3 I also reduce my working time & 3.57 \\
\hline \multicolumn{2}{|l|}{ Panel C } \\
\hline \multicolumn{2}{|c|}{$\begin{array}{c}\text { Your club receives larger government subsidies. } \\
\text { Would you adapt your labor supply? }\end{array}$} \\
\hline 1 Yes - Increase & 30.32 \\
\hline 2 No - Unchanged & 68.58 \\
\hline 3 No - Reduce & 1.10 \\
\hline
\end{tabular}

Panel A of Table 4 shows the distribution of answers (results are for those volunteers for which we have data on the MQI). The majority of about $62 \%$ of volunteers answered that they would not alter their labor supply if other volunteers would increase labor supply. Approximately $33 \%$ would increase their labor supply, and 5\% answered that they would reduce their labor supply.

Panel B summarizes descriptive statistics for the question how a volunteer would change his or her labor supply if other volunteers of the sports club would decrease their labor supply. Volunteers could choose among the three categories 'I would compensate', 'I do not care', and 'I reduce my volunteer work'. In total, $47 \%$ of volunteers answered that they would compensate the reduction of work effort by others, and $49 \%$ answered that they do not care what other volunteers do.

Panel C shows summary statistics for the question how a volunteer would change his or her labor supply if the sports club would receive additional public subsidies. The results show 
that $68 \%$ of volunteers answered that an increase in public subsidies would not affect their labor supply, while $30 \%$ answered that they would expand their labor supply.

Summing up, the descriptive statistics show evidence of a dominating crowding-in effect in the case of public subsidies and in case that other volunteers increase their work effort. This crowding-in effect is consistent with the view that public subsidies and volunteer labor supply, and the labor supply of different volunteers, are complements. Such a complementarity is consistent with human-capital theories of volunteer labor supply. There is also evidence, however, that a non-negligible proportion of volunteers does not alter labor supply in response to public subsidies and/or an increase in the volunteer labor supply of others. Such an invariance is consistent with private-consumption theories of volunteer labor supply. Finally, the observed large proportion of volunteers who would increase their labor supply in response to a reduction of work effort by other volunteers is consistent with the view that there is a substitutability of labor supply of different volunteers, which is consistent with public-goods theories of volunteer labor supply. Hence, all three categories of economic theories of volunteer labor supply help to explain different facets of the data. In addition, the descriptive statistics show the presence of an asymmetry insofar as it seems to matter for the complementarity/substitutability of volunteer labor supply whether other volunteers increase or decrease their work effort.

\section{Empirical Results}

\subsection{MQI, Outcomes, and Social Capital}

Table 5 shows the MQI as a function of the outcomes of volunteering. Panel A summarizes the results for outcomes of volunteering. The MQI is higher for those volunteers who answered that volunteering in their sports club is an important part of their life, who are often up to the challenges of their volunteer work, and who are content with their volunteer work and the support they receive from their sports club. Hence, match quality is positively correlated with outcomes of volunteering, a result that is consistent with findings reported in earlier research (Emrich \& Pierdzioch, 2016). We also found a positive correlation between the MQI and (log) hours volunteered per week. The correlation is 0.16 , where the $95 \%$ confidence interval ranges from 0.12 to $0.20(\mathrm{t}=7.77, \mathrm{p}$-value $<0.01)$.

The results summarized in Table 6 on the correlation between the MQI and measures of social capital are also consistent with findings documented in earlier literature. The results show that the MQI is higher on average for those volunteers who disagree with the statement that 
Table 5: MQI and Outcomes of Volunteering

\begin{tabular}{llr}
\hline \hline Questions/Statements & Answers & MQI (mean) \\
\hline How important is your volunteer work to you? & Very important & 128.55 \\
& Important & 109.31 \\
& So, so & 89.65 \\
& Less important & 77.87 \\
& Unimportant & 51.20 \\
\hline Are you up to the challenges of your voluntary work? & Always & 110.99 \\
& Most of the time & 107.97 \\
& Sometimes & 96.72 \\
& Seldom & 85.17 \\
How content are you with your volunteer work? & Never & 33.00 \\
& Very content & 124.35 \\
& Content & 108.08 \\
& So, so & 96.60 \\
& Discontent & 83.27 \\
How content are you with your club's support? & Very Discontent & 64.15 \\
\hline & Very content & 122.78 \\
& Content & 108.64 \\
& Partly content & 100.68 \\
& Discontent & 102.31 \\
& Very discontent & 111.13 \\
\hline
\end{tabular}

the sense of community in their sports club is declining. Consistent with findings reported by Stukas et al. (2005), match quality is higher for those volunteers who answered that they generally trust others. Interestingly, however, the MQI is also higher for those volunteers who agreed that they generally trust members of their sports club more than others. Match quality, thus, is positively correlated with a binding but also with a bonding component of social capital (Behrens et al., 2016).

When we compared the averages of the MQI for the 'fully agree' categories with the averages we obtained for the 'fully disagree' categories we obtained statistically highly significant results (sense of community: $\mathrm{t}=7.09, \mathrm{p}$-value $<0.01$; general trust: $\mathrm{t}=-2.68, \mathrm{df}=24.19$, $\mathrm{p}$-value $=0.01$; trust members of my club more than others: $\mathrm{t}=-8.17$, p-value $<0.01$ )

\subsection{Match Quality and Crowding Out/In}

Table 7 shows the MQI for the categories of the crowding-out/crowding-in questions. The MQI is higher on average for those volunteers who would increase their labor supply when 
Table 6: MQI and Social Capital

\begin{tabular}{llr}
\hline \hline Questions/Statements & Answers & MQI (mean) \\
\hline The sense of community in our club is declining. & Fully disagree & 118.92 \\
& Mostly disagree & 111.31 \\
& So, so & 108.34 \\
& Mostly agree & 105.14 \\
& Fully agree & 98.21 \\
\hline I generally trust others. & Fully disagree & 95.21 \\
& Mostly disagree & 103.46 \\
& So, so & 104.06 \\
& Mostly agree & 109.07 \\
& Fully agree & 116.91 \\
\hline I generally trust members of my club more than others. & Fully disagree & 102.84 \\
& Mostly disagree & 103.21 \\
& So, so & 108.36 \\
& Mostly agree & 115.39 \\
\hline \hline
\end{tabular}

others also increase their labor supply. The MQI is also higher for those volunteers who would compensate a reduction of labor supply by other volunteers. Furthermore, the MQI is higher for those volunteers who would increase their labor supply if their sports club would receive additional government subsidies. Hence, our results recover an interesting asymmetry. Our findings imply that a complementarity of volunteer labor supply and, thus, a crowding-in effect is at work when others (including the state) would increase their contributions. At the same time, however, a substitutability of volunteer labor supply consistent with a crowding-out effect appears is at work when others would reduce their work effort.

Because we have few observations for some of the categories of the crowding-out/crowding-in questions, we tested the statistical significance of the differences between the average MQIs by forming two categories for every crowding-out/crowding-in question. With regard to the question how a volunteer would change his or her labor supply when others increase their labor supply by one hour per week, we formed the categories 'would not increase labor supply' and 'would increase labor supply'. The difference between the average MQIs for these two categories turned out to be statistically highly significant $(t=-6.86$, p.value $<0.01)$. Similarly, we formed the two categories 'do not care or reduce labor supply' and 'compensate the reduction by increasing their labor supply' for the question 'What would you do when other volunteers reduce their labor supply?'. Again, the difference between the average MQIs for 
Table 7: MQI and the Crowding-Out/Crowding-In Hypotheses

\begin{tabular}{|c|c|}
\hline Answers & $\overline{(\text { mean) }}$ \\
\hline \multicolumn{2}{|l|}{ Panel A } \\
\hline \multicolumn{2}{|c|}{$\begin{array}{c}\text { Other volunteers increase their labor supply by one hour per week. } \\
\text { How would you adapt your labor supply? }\end{array}$} \\
\hline 1 No - Reduction by more than one hour & 92.81 \\
\hline 2 No - Reduction by one hour & 110.58 \\
\hline 3 No - Reduction by less than one hour & 105.85 \\
\hline 4 No - Unchanged & 105.46 \\
\hline 5 Yes - Increase by less than one hour & 112.46 \\
\hline 6 Yes - Increase by one hour & 116.17 \\
\hline 7 Yes - Increase by more than one hour & 115.12 \\
\hline \multicolumn{2}{|l|}{ Panel B } \\
\hline \multicolumn{2}{|c|}{$\begin{array}{l}\text { Other volunteers reduce their labor supply. } \\
\text { How would you adapt your labor supply? }\end{array}$} \\
\hline 1 I compensate the reduction by working more & 113.50 \\
\hline 2 I do not care & 104.71 \\
\hline 3 I also reduce my working time & 99.82 \\
\hline \multicolumn{2}{|l|}{ Panel C } \\
\hline \multicolumn{2}{|c|}{$\begin{array}{l}\text { Your club receives larger government subsidies. } \\
\text { Would you adapt your labor supply? }\end{array}$} \\
\hline 1 Yes - Increase & 115.02 \\
\hline 2 No - Unchanged & 105.93 \\
\hline 3 No - Reduce & 94.38 \\
\hline
\end{tabular}

these two categories was significant $(\mathrm{t}=-6.56, \mathrm{p}$-value $<0.01)$. As for the question what a volunteer would do if the sports club received additional public subsidies we formed the two categories 'unchanged or reduce' and 'increase' labor supply and found that the average MQI is significantly smaller in the former category than in the latter $(\mathrm{t}=-6.13$, $\mathrm{p}$-value $<0.01)$.

\subsection{Regression Model}

The answers given by volunteers to the crowding-in/crowding-out questions most likely do not only depend upon match quality alone. For example, the willingness to expand labor supply in case other volunteers shrink their work effort may not only depend on the MQI but also on how important volunteer work is for a volunteer and how satisfied he or she is with their volunteer work. Rather, it is important to study the partial correlation of the MQI with the answers to the crowding-in/crowding-out questions, that is, the effects that obtain after accounting for the interfering effects of other potentially influential sociodemographic 
Table 8: Regression Model

\begin{tabular}{lrrr}
\hline \hline Crowding-out/crowding-in question & MQI & t-value & $N$ \\
\hline 1 Other volunteers increase their labor supply. & 0.0073 & 3.6207 & 1251 \\
2 Other volunteers reduce their labor supply. & -0.0027 & -1.3251 & 1239 \\
3 Your club receives larger government subsidies. & -0.0048 & -2.1809 & 1257 \\
\hline Control variables: importance of volunteering, satisfaction, shortage of volunteers \\
in the sports club, reliogiosity, interest in politics, financial situation, children. \\
\hline \hline
\end{tabular}

variables. For this reason, we estimated a multivariate regression model. In addition to match quality, we included several sociodemographic control variables in the model.

In order to proxy for time constraints imposed by a a volunteer's family life we asked whether a volunteer has children. We also controlled for a volunteer's overall financial situation (5point scale from 'poor' to 'very good') because the answers to the crowding-in/crowding-out questions may depend on whether a volunteer can afford expanding his or her labor supply. We also controlled for a volunteer's general humanitarian values by including data on religiosity and interest in politics (both measured using a 5-point scale from 'not at all' to 'very strong') in the regression model. Finally, we asked volunteers whether there is a general shortage of volunteers in their sports club (coded as a binary variable; 'yes' or 'no'), and we added the answers to the questions how important is volunteering and how content are volunteers with their work to the list of control variables.

Because of the ordered structure of the answer categories for the crowding-in/crowding-out questions, we estimated the regression model in the form of an ordered probit model. The results summarized in Table 8 show that match quality is significantly correlated with the responses of the crowding-in/crowding-out questions even after accounting for the influence of the sociodemographic control variables. Further inspection of the marginal effects showed that match quality shifts probability to the complementarity (substitutionality) categories in case others increase their volunteer labor or the sports club receives additional public subsidies (others reduce their volunteer labor supply), corroborating the results of the bivariate correlation analyses.

\section{Concluding Remarks}

Based on data from an online questionnaire study of volunteers of German sports clubs, we studied how outcomes of volunteering, social capital, and volunteers towards a crowding- 
in/crowding-out effect are correlated with match quality. We measured match quality by means of an index that aggregates the congruence of a volunteer's motives for doing volunteer work with utility experiences from volunteer work along several motive/utility dimensions. The match quality index is positively correlated with various outcomes of volunteering and with measures of social capital. However, while match quality appears to be positively correlated with the bridging component of social capital, we also found evidence that match quality reinforces the bonding component of social capital. While we measured the former in terms of a volunteer's general trust in others, we measured the latter by asking volunteers whether they trust members of their sports club more than other members of society.

We further found that match quality is on average higher for volunteers who would increase their labor supply if other volunteers of their sports club would increase their work effort. In this case, match quality is positively associated with a complementarity of volunteer labor supply and a crowding-in effect. Similarly, we found that match quality is higher for those volunteers who would expand their labor supply in case their sports club would receive additional public subsidies. In contrast, we also found that match quality is higher for volunteers who would compensate a reduction in labor supply by other volunteers. In this case, match quality appears to strengthen a substitutionality of volunteer labor supply and a crowding-out effect.

One interpretation of our complementarity/substitutionality result is that volunteer preferences depend on the social setting. In this context, Bosworth, Singer, and Snower (2016) introduce a model in which responsive agents adjust to changing social environments. Consistent with our approach to measuring match quality, they argue that individuals exhibit multiple discrete motives. Different motives can be activated in different social settings. Applied to our research, it seems that the information that other volunteers increase their working time or the state increases a club's funding activates egoistic motives. If volunteers were interested in the total supply of a club good, as stipulated by models of the public-goods type, they would simply decrease their labor supply in such a social environment. However, once the social setting changes, i.e., other volunteers decrease their working hours and the club's public good production threatens to decline, volunteers with a high match quality step up in order to sustain production of the club's public good. Hence, these volunteers experience a shift towards altruistic preferences in the sense assumed in public-goods models. 


\section{References}

Abrams, B.A., \& Schitz, M.D. (1978). The 'crowding-out' effect of governmental transfers on private charitable contributions. Public Choice, 33, 29-39.

Andreoni, J. (1989). Giving with impure altruism: Applications to charity and Ricardian equivalence. Journal of Political Economy, 97, 1447-1458.

Andreoni, J. (1990). Impure altruism and donations to public goods: A theory of warm-glow giving. Economic Journal, 100, 464-477.

Andreoni, J., \& Payne, A.A. (2003). Do government grants to private charities crowd out giving or fund-raising? American Economic Review, 93, 792-812.

Andreoni, J., \& Payne, A.A. (2011). Is crowding out due entirely to fundraising? evidence from a panel of charities. Journal of Public Economics, 95, 334-343.

Behrens, C., Emrich, E., Meyer, T. \& Pierdzioch, C. (2016). Football clubs and philanthropy: An empirical analysis of volunteering, match quality, and donations. International Review for the Sociology of Sport. Advance online publication. doi: 10.1177/1012690216672653.

Bergstrom, T., Blume, L., \& Varian, H. (1986). On the private provision of public goods. Journal of Public Economics, 29, 25-49.

Borgonovi, F. (2006). Do public grants to American theatres crowd-out private donations? Public Choice, 126, 429-451.

Bosworth, S.J., Singer, T., \& Snower, D.J. (2016). Cooperation, motivation and social balance. Journal of Economic Behavior and Organization, 126, 72-94.

Brooks, A.C. (2000). Public subsidies and charitable giving: Crowding out, crowding in, or both? Journal of Policy Analysis and Management, 19, 451-464.

Davis, M.H., Hall, J.J., \& Meyer, M. (2005). The first year: Influences on the satisfaction, involvement, and persistence of new community volunteers. Personality and Psychology Bulletin, 29, 248-260.

De Wit, A., \& Bekkers, R. (2016). Government support and charitable donations: A meta-analysis of the crowding-out hypothesis. Journal of Public Administration Research and Theory. Advance online publication. doi: 10.1093/jopart/muw044. 
De Wit, A., Bekkers, R., \& van Groenou, M.B. (2016). Heterogeneity in crowding-out: When are charitable donations responsive to government support? European Sociological Review, 33, 59-71.

Emrich, E., \& Pierdzioch, C. (2015). Testing economic models of volunteer labor supply: Some empirical evidence for the German Red Cross. Applied Economics, 47, 4247-4259.

Emrich, E., \& Pierdzioch, C. (2016). Volunteering, match quality, and internet use. Schmollers Jahrbuch, 136, 199-226.

Ferris J.S., \& West, E.G. (2003). Private versus public charity: Reassessing crowding out from the supply side. Public Choice, 116, 399-417.

Harbaugh, W.T. (1998). What do donations buy? A model of philanthropy based on prestige and warm glow. Journal of Public Economics, 67, 269-284.

Heutel, G. (2014). Crowding out and crowding in of private donations and government grants. Public Finance Review, 42, 143-175.

Horne, C., Johnson, J.L., \& van Slyke, D.M. (2005). Do charitable donors know enough - and care enough - about government subsidies to affect private giving to nonprofit organizations? Nonprofit and Voluntary Sector Quarterly, 34, 136-149.

Khanna, J., \& Sandler, T. (2000). Partners in giving: The crowding-in effects of UK government grants. European Economic Review, 44, 1543-1556.

Kim, M., \& van Ryzin, G.G. (2014). Impact of government funding on donations to arts organizations: A survey experiment. Nonprofit and Voluntary Sector Quarterly, 43, $910-925$.

Kingma, B.R. (1989). An accurate measurement of the crowd-out effect, income effect, and price effect for charitable contributions. Journal of Political Economy, 97, 1197-1207.

Menchink, P.L., \& Weisbrod, B.A. (1987). Volunteer labour supply. Journal of Public Economics, 32, 159-183.

Nikolova, M. (2015). Government funding of private voluntary organizations: Is there a crowding-out effect? Nonprofit and Voluntary Sector Quarterly, 44, 487-509.

Payne, A.A. (1998). Does the government crowd-out private donations? New evidence from a sample of non-profit firms. Journal of Public Economics, 69, 323-345. 
R Core Team (2015). R: A Language and Environment for Statistical Computing. R Foundation for Statistical Computing, Vienna, Austria. http://www.R-project.org/.

Ribar, D.C., \& Wilhelm, M.O. (2002). Altruistic and joy-of-giving motivations in charitable behavior. Journal of Political Economy, 110, 425-457.

Roberts, R.D. (1984). A positive model of private charity and public transfers. Journal of Political Economy, 92, 136-148.

Schiff, G. (1980). Charitable giving and government policy: An economic analysis. Westport, Connecticut: Greenwood Press.

Simmons, W.O, \& Emanuele, R. (2004). Does government spending crowd out donations of time and money? Public Finance Review, 32, 498-511.

Smith, T.M. (2007). The impact of government funding on private contributions to nonprofit performing arts organizations. Annals of Public and Cooperative Economics, 78, $137-160$.

Sokolowski, S.W. (2013). Effects of government support of nonprofit institutions on aggregate private philanthropy: Evidence from 40 countries. Voluntas, 24, 359-381.

Steinberg, R. (1991). Does government spending crowd out donations? Interpreting the evidence. Annals of Public and Cooperative Economics, 64, 591-612.

Stukas, A.A., Daly, M., \& Cowling, M.J. (2005). Volunteerism and social capital: A functional approach. Australian Journal on Volunteering, 10, 35-44.

Stukas, A.A., Worth, K.A., Clary, E.G., \& Snyder, M. (2009). The matching of motivations to affordances in the volunteer environment - An index for assessing the impact of multiple matches on volunteer outcomes. Nonprofit and Voluntary Sector Quarterly, 38, $5-28$.

Tschirhart, M., Mesch, D.J., Perry, J.L., Miller, T.K., \& Lee, G. (2001). Stipended volunteers: Their goals, experiences, satisfaction and likelihood of future service. Nonprofit and Voluntary Sector Quarterly, 30, 422-443.

Wicker, P., Breuer, C., \& Hennings, B. (2012). Understanding the interactions among revenue categories using elasticity measures - evidence from a longitudal sample of nonprofit sport clubs in Germany. Sport Management Review, 15, 318-329. 
Ziemek, S. (2006). Economic analysis of volunteers' motivations - A cross-country study. Journal of Socio-Economics, 35, 532-555. 